\title{
BIFURCATION OF COMMON CAROTID ARTERY IN RELATION TO VERTEBRAL LEVEL IN NEPALESE: A CADAVERIC STUDY
}

\author{
Usha Chalise, Allin Pradhan, Chhiring Palmu Lama, Shaligram Dhungel
}

Department of Human Anatomy, Nepal Medical College and Teaching Hospital, Attarkhel, Gokarneshwor-8, Kathmandu, Nepal

\begin{abstract}
The principal arterial supply of the head and neck are the two Common Carotid Arteries (CCA), they ascend in the neck and each divides into two branches, the External Carotid Artery (ECA) supplying the exterior of the head, neck and the Internal Carotid Artery (ICA) supplying the cranial and orbital cavities. Atherosclerosis of the carotid arteries is a major cause of stroke and transient ischemic attack and it increases with age. The present study was observational based descriptive type, conducted to identify the CCA bifurcation in relation to cervical vertebral level. A total number of 18 cadavers (16 males and 2 females), right and left side of cadavers were studied by dissection method in the Department of Anatomy, NMCTH from February 2020 to February 2021. The ethical approval was taken from NMC- IRC (Ref no- 026-076/077). In present study the frequency of CCA bifurcation in sixteen male Nepalese cadavers (32 samples) on the right and left side was observed and found high level of bifurcation on $31.25 \%$ and $37.5 \%$ respectively and normal/ standard on the right and left on $68.75 \%$ and $62.5 \%$ and there were no findings of low bifurcation of CCA. In two female cadavers (4 observations) the level of bifurcation was same on both the side at the level of C3-C4. The Carotid artery injury is possible in different neurological and head and neck surgery. Therefore, the knowledge of variation in level of bifurcation of CCA in different population will be referential to reduce the iatrogenic injury.
\end{abstract}

\section{KEYWORDS}

Common Carotid Arteries (CCA), External Carotid Artery (ECA), Internal Carotid Artery (ICA) and Cervical vertebral level (C1-C5)

Received on: May 12, 2021

Accepted for publication: September 12, 2021

\section{CORRESPONDING AUTHOR}

Dr. Usha Chalise,

Assistant Professor

Department of Human Anatomy, Nepal Medical College and Teaching Hospital, Attarkhel, Gokarneshwor-8,

Kathmandu, Nepal

Email: drushachalise@gmail.com

Orcid No: https://orcid.org/0000-0001-7326-5630

DOI: https://doi.org/10.3126/nmcj.v23i3.40380 


\section{INTRODUCTION}

The principal arterial supply of the head and neck are the two Common Carotid Arteries (CCA), they ascends in the neck and each divides into two branches, the External Carotid Artery (ECA) supplying the exterior of the head, face, greater part of neck and the Internal Carotid Artery (ICA) supplying to the parts within the cranial and orbital cavities (Fig. 1). ${ }^{1}$

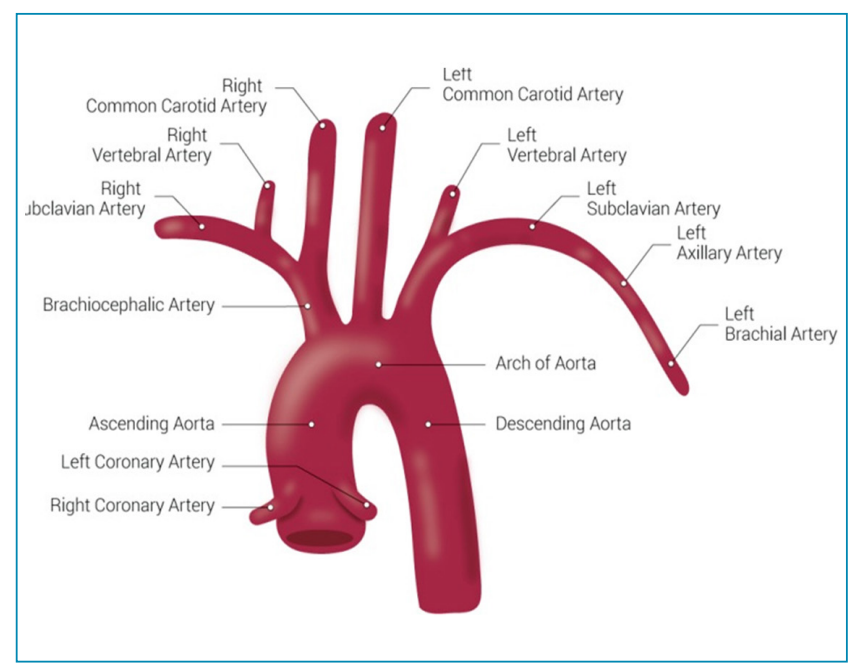

Fig. 1: Branches of Arch of aorta

The neck is the transitional area between the base of the cranium superiorly and the clavicles inferiorly. ${ }^{2}$ Many important structures are crowded together in the neck, such as muscles, glands, arteries, veins, nerves, lymphatics, trachea, esophagus, and vertebrae (cervical segment of the spinal cord). Hence, the neck is a well-known region of vulnerability. ${ }^{3,4}$

The anteromedial position of the external carotid artery in relation to the internal carotid artery is the most common anatomical position. ${ }^{5}$ The level of the carotid bifurcation is usually defined in relation to bony or cartilaginous structures of the neck, that is, cervical vertebra posteriorly and hyoid bone and thyroid cartilage anteriorly. ${ }^{6}$

The carotid bifurcation can occur as high as at the level of the hyoid bone, or as low as at the level of the cricoid cartilage. Conventional angiography is considered as the most reliable method for diagnosis of carotid bifurcation diseases, such as stenosis. ${ }^{7,8}$

The Common carotid artery and its branches are the most important vessels in the neck. These vessels are susceptible to injury during various surgical procedures, neck dissections, and orthopedic surgeries of cervical vertebra. A high common carotid artery bifurcation possesses a higher risk of being hit by intraarticular screws during orthopedic procedures on cervical vertebra. ${ }^{3,9,10}$ The disruption of CCA, ECA and ICA may cause a bleeding that can threaten life.

Atherosclerosis of the carotid arteries is a major cause of stroke and transient ischemic attack and it increases with age. ${ }^{11}$ Carotid Plaques typically form in the common carotid artery bifurcation and extend distally into the internal carotid arteries. ${ }^{3,12}$ The causes of this is due to developmental source because the internal carotid is developed as the continuation of common carotid artery and the external carotid is developed as sprouting from third arch. ${ }^{13}$

The carotid coils sometime occur in the elderly, in whom atherosclerosis is also frequently seen. The coiling of the external carotid artery may be acquired from the excessive elongation of the artery with age. ${ }^{14}$ The angiography is considered as the most reliable method for diagnosis of carotid bifurcation diseases, such as stenosis. ${ }^{7}$ The knowledge of anatomy of carotid artery bifurcation is important for vascular surgeon in the neck, radical neck dissections, carotid sinus baroreceptor stimulation, catheterizations, aneurysms and to minimize the complication related to them. ${ }^{6,11,14}$

The surgeon should take precaution during surgery in presence of a high Common carotid artery bifurcation because of the closer proximity of hypoglossal nerve and is more vulnerable during surgery. Preoperative documentation of the level of the CCA bifurcation is necessary to prevent the risk of iatrogenic injury. ${ }^{15,16}$ Carotid artery injury is a potentially devastating event that can occur in low lying bifurcation of common carotid artery during anterior cervical approaches by Neurosurgeon, which can be reduced by using operating microscope. ${ }^{17}$

\section{MATERIALS AND METHODS}

The present study was observation based descriptive type, conducted to identify the CCA bifurcation in relation to cervical vertebral level. A total number of 18 cadavers (16 male and 2 female), right and left side of head and neck region of cadavers and previously dissected cadaveric specimens were also utilized in the study available in the department. In total comprising of 36 specimen were observed during routine dissection in the Department of Anatomy, Nepal Medical College and Teaching Hospital (NMCTH) from February 2020 to February 2021. The ethical approval 


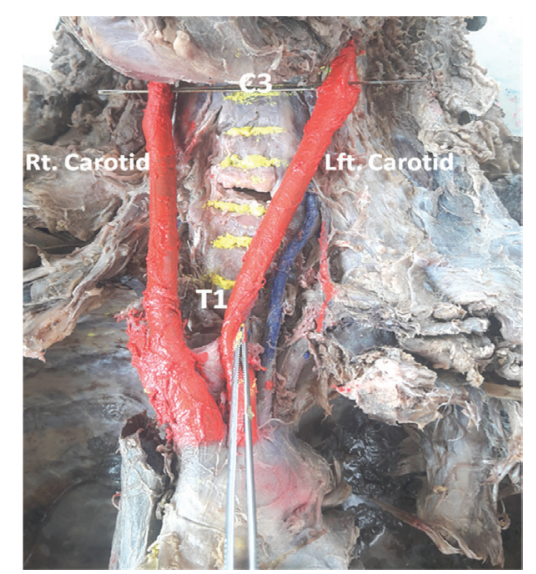

Fig. 2: Normal branching pattern of common carotid artery

was obtained from NMC-IRC (Ref. no- 026076/077).

Exclusion criteria:

1. The cadavers which were dry and difficult to dissect and those found to be damaged by students

2. Cadavers of having their age below 24 years and

3. Cadavers exhibiting any form of deformity and surgical scars in neck region were excluded from the study.

Operational definitions - High bifurcation is

Table 1: Level of bifurcation of CCA in relation to cervical vertebra in male

\begin{tabular}{|lcc|}
$\begin{array}{l}\text { Vertebral } \\
\text { level }\end{array}$ & $\begin{array}{c}\text { Level of } \\
\text { bifurcation } \\
\text { on right side }\end{array}$ & $\begin{array}{c}\text { Level of } \\
\text { bifurcation on } \\
\text { left side }\end{array}$ \\
C2-C3 & 0 & 2 \\
C3 & 5 & 4 \\
C3-C4 & 9 & 9 \\
C4 & 2 & 1 \\
C5 & 0 & 0 \\
\hline
\end{tabular}

the bifurcation of CCA at the level of $3^{\text {rd }}$ or above $3^{\text {rd }}$ cervical vertebrae, Standard (common) bifurcation is when bifurcation at the level of $4^{\text {th }}$ cervical vertebra or between $3^{\text {rd }}$ and $4^{\text {th }}$ cervical vertebra (Fig. 2) and low bifurcation when CCA bifurcates below $4^{\text {th }}$ cervical vertebra. ${ }^{18}$

Procedures/methods - CCA was exposed on the right and left side of the cadavers by the dissection method adopting routine standard procedure of dissection (Cunningham's manual of dissection volume III). ${ }^{19}$ All dissections were carried out on the cadavers placed in supine position on a dissection table with the neck in neutral position. Bilateral CCA, ECA and ICA were dissected and exposed. The anatomical relationship between the CCA bifurcation and of cervical vertebra/inter vertebral disc was observed in all study sample with the help of straight wire or needle. The Photographs were taken using digital camera and the data

Table 2: Level of bifurcation of CCA in relation to cervical vertebra in female

\begin{tabular}{|ccc|}
$\begin{array}{l}\text { Vertebral } \\
\text { level }\end{array}$ & $\begin{array}{c}\text { Level of } \\
\text { bifurcation on } \\
\text { Right side }\end{array}$ & $\begin{array}{c}\text { Level of } \\
\text { bifurcation on } \\
\text { left side }\end{array}$ \\
C3-C4 & 2 & 2 \\
\hline
\end{tabular}

observed were recorded. Then the collected data was divided by sides for description of their distribution in the left and right sides of each gender. The figures and Tables were used for presentation of the results and analysis was performed manually. ${ }^{3}$

\section{RESULTS}

Common carotid arteries are the main arterial supply to the head and neck region. They divide in the neck in to external and internal carotid artery which supply the oxygenated blood to the face/neck region and the brain respectively. The artery had variation pattern at their

Table 3: Showing the variation of bifurcation pattern of CCA in male

\section{Level of bifurcation on right side}

High bifurcation

Standard bifurcation

Low bifurcation
5

11

0

\section{Level of bifurcation} on left side

6

10

0

\section{Frequency}

11

21

0
$\%$

R-31.25

L-37.5

R-68.75

L-62.5

0\% 


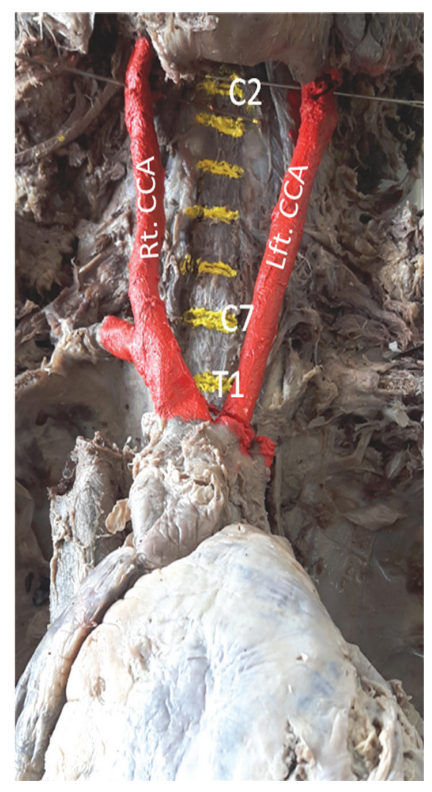

Fig. 3: High bifurcation type of common carotid artery (C2-C3)

bifurcation in relation to cervical vertebra. The observation was tabulated below:

In present study the frequency of CCA bifurcation in sixteen male Nepalese cadavers (32 samples) on the right and left side was observed and found high level of bifurcation on $31.25 \%$ and $37.5 \%$ respectively and normal/ standard on the right and left on $68.75 \%$ and $62.5 \%$. and there was no findings of low bifurcation of CCA. In two female cadavers (4 observations) the level of bifurcation was same on both the side at the level of C3-C4 (Table: 1 , 2 and 3 ).

\section{DISCUSSION}

In past several studies have been carried out to identify the level of bifurcation of CCA in relation to cervical vertebra in different populations. Some of them have been mentioned here.

In present study the frequency of CCA bifurcation in sixteen male Nepalese cadavers on the right and left side is high $31.25 \%$ and $37.5 \%$ respectively and normal/ standard on the right and left on $68.75 \%$ and $62.5 \%$ (fig. 3 and 4 ). The findings of the present study is resembling with the study conducted by Ito \& associates as they reported a high common carotid artery bifurcation in 25 [31.2\%], standard bifurcation in 46 [57.5\%], low bifurcation in 9 [11.3\%] in a total of 80 cases. $^{1}$

The findings of the present study is inconsistent to the study conducted by Vatsala on fourty cadavers (80 carotid arteries), in Davenger,

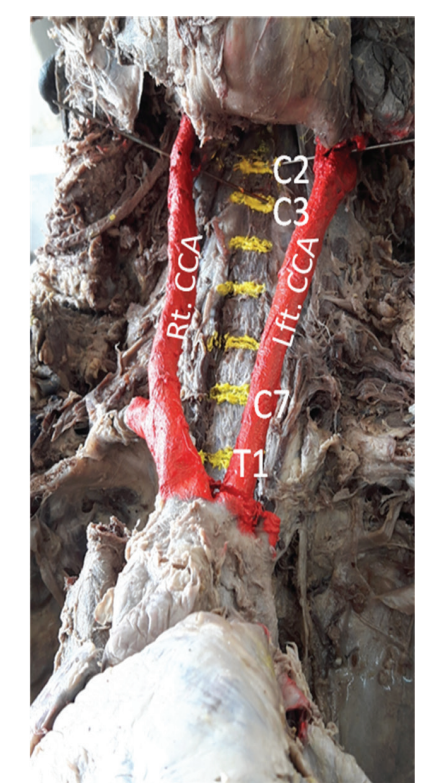

Fig. 4: Variation in branching pattern of common carotid artery (C2 on left side and C3 on right side)

India where the normal bifurcation was $23.7 \%$, high on $62.5 \%$ and low on $13.75 \% .^{1}$ The findings of current study also differs from the study performed by Woldeyes on thirteen cadavers (26 specimen) in Ethiopian, where the bifurcation of CCA was high at the of C3 on $46.15 \%$ and normal at the level of $\mathrm{C} 4$ on $38.8 \% .^{3}$

The findings of this study is different than the findings of other study mentioned by Woldeyes ${ }^{3}$ where in Japanese $(80$ sides $)$ standard bifurcation was on 57\%, high bifurcation on $31.2 \%$ and low bifurcation on $11.3 \%$. The findings of Woldeyes (26 specimen) performed in Ethyopia was similar to this study where the low bifurcation was $0 \%$.

The findings of current study is similar to the findings of the CT Angiogram study of Indian population conducted by Badhe et $a l^{9}$ on 200 patients concluded that the maximum number of patients having carotid bifurcation at C3 level 96 patients and on the left side 103 patients on that level. The minimum number or 3 patients having bifurcation at $\mathrm{C} 5$ on both right and left side.

The conclusion of this study is different than the study conducted by Vinaitha, ${ }^{12}$ where the normal bifurcation at C3-C4 in 22.5\%, and high at $\mathrm{C} 3$ on $38.8 \%$ and also concluded that the maximum number of CCA bifurcation at the level of C3 in $60 \%$ cases of left side and in 55\% on right side.

In other study performed by Shivaprakash et $a l^{17}$ on fifty carotid arteries in Manglore India, the bifurcation of CCA at the level of C3-C4 in 
$38 \%$, high on $40 \%$ and low on $22 \%$ and also concluded that in $72 \%$ of cadavers where the CCA bifurcation at same level both the side which is also different than our findings. The findings of Arteria and Relación, ${ }^{20}$ was similar to the findings of current study that the bifurcation on the left side was more variable than on the right side.

The knowledge of vascular anatomy with its variation is essential for interpretation of diagnostic and interventional procedures as in carotid angiography, stent placement in carotid artery blockage. The Carotid artery injury is possible in different neurological and head \& neck surgery that can occur during anterior cervical approaches. Therefore the knowledge of variation in level of bifurcation of CCA in different population will be referential to reduce the iatrogenic injury.

\section{ACKNOWLEDGEMENTS}

I would like to thank all the faculties and staffs of Department of Anatomy, NMCTH.

Conflict of interest: None

Source of research fund: None

\section{REFERENCES}

1. Vatsala AR, Ajay KT, Mavishettar GF, Sangam. A study of anatomical variations of the common carotid arteries: a cadaveric study. Int'l J Anat Res 2014; 2: 262-65. issn 2321- 4287.

2. Moore K, Dalley A, Agur A. Anterior cervical region: Clinically Oriented Anatomy, $7^{\text {th }} \mathrm{ed}, 2010$.

3. Woldeyes DH. Anatomical variations of the common carotid artery bifurcations in relation to the cervical vertebrae in Ethiopia. Anat Physiol 2014; 4: 3.

4. Anu VR. Clinically- relevant variations of the carotid arterial system. Singapore Med J 2007; 48: 566-9.

5. Standring S (ed. in chief). Gray's Anatomy. 39th ed. Elsevier Churchill Livingstone, 2005: 543-54

6. Ambali M, Jadhav S. Variationin bifurcation point and branching pattern of Common Carotid arteries: A cadaveric study. J Pharm Biomed Sci 2012; 25: 147-51.

7. Radha K. Bifurcation levels of the common carotid arteries: a cadaveric study in south Indian population. Int'l J Anat Res 2014; 2: 511-4.

8. Al-Rafiah A, EL-Haggagy AA, Aal IHA, Zaki AI. Anatomical study of the carotid bifurcation and origin variations of the ascending pharyngeal and superior thyroid arteries. Asian J Clin Diagn Res 2011; 70: 47-55.

9. Badhe P, Dabharde P, Kapadnis AS, Dasari RK. Anatomical variation of Common Carotid artery bifurcation in relation to cervical vertebra on CT angiogram. J Dent Med Sci 2018; 17: 58-66.

10. Furukawa S, Wingenfeld L, Takaya A, Nakagawa T, Sakaguchi I, Nishi K. Morphological variation of the carotid artery bifurcation level. OMICS Online 2012; 1: 135. doi:10.4172/ scientificreports.135

11. Woo SY, Joh JH, Han SA, Park HC. Prevalence and risk factors for atherosclerotic carotid stenosis and plaque: a population-based screening study. Med 2017; 96: e5999.

12. Vinaitha D, Anandhi KS, Saran RS, Ramanathan L, Subramaniam A. High bifurcation of the common carotid artery and looping of the external carotid artery-a case report. J Clin Diagn Res 2012; 6: 462-4.

13. Sadler TW. Langman's Medical Embryology. $11^{\text {th }}$ Edition pg 186-8.

14. Woo SY, Joh JH, Han SA, Park HC. Prevalence and risk factors for atherosclerotic carotid stenosis and plaque: a population-based screening study. Med 2017; 96: e5999.

15. Lo A, Oehley M, Bartlett A, Adams D, Blyth P, Al Ali. Anatomical variations of the common carotid artery bifurcation. Aust New Zeal J Surg 2006; 76: 970-2.

16. Lucev N, Bobinac D, Maric I, Drescik I.Variations of the great arteries in the carotid triangle. Otolaryngol Head Neck 2000; 122: 590-1.

17. Shivaprakash S, Vijaykumar AG, Nagar BG. Bifurcation of common carotid artery: a cadaveric study in south Indian population. Int'l J Health Sci Res 2014; 4: 1-221.

18. Ozgur Z, Govsa F, Ozgur T. Anatomic evaluation of the carotid artery bifurcation in cadavers: implications for open and endovascular therapy. Surg Radio Anat 2008; 30: 475-80. doi: 10.1007/ s00276-008-0351-4.

19. Romanes GJ. Cunningham's Manual of Practical Anatomy: 15 ed, Volume 3, Head and neck and Brain. Oxford University Press 1996; 22: 35.

20. Arteria ND, Relación CC. Common carotid artery bifurcation levels related to clinical relevant anatomical landmarks. Int'l J Morphol 2006; 24: 413-6. ISSN 0717-9502. 